\title{
Correction to: Ergonomic analysis of laparoscopic and robotic surgical task performance at various experience levels
}

\author{
Jorge G. Zárate Rodriguez ${ }^{1} \cdot$ Ahmed M. Zihni $^{2} \cdot$ Ikechukwu Ohu $^{3} \cdot$ Jaime A. Cavallo $^{4} \cdot$ Shuddhadeb Ray ${ }^{1}$. \\ Sohyung $\mathrm{Cho}^{5}$. Michael M. Awad ${ }^{1}$
}

Published online: 22 November 2021

๑) Springer Science+Business Media, LLC, part of Springer Nature 2021

\section{Correction to: Surgical Endoscopy (2019) 33:1938-1943 https://doi.org/10.1007/s00464-018-6478-4}

In the original article, the middle bar graph in Fig. 2 (TL surgeons) was erroneously duplicated in the bottom (RAL surgeons).

Below is the corrected version of Fig. 2.

The original article can be found online at https://doi.org/10.1007/ s00464-018-6478-4.

\section{Jorge G. Zárate Rodriguez}

j.zarate@wustl.edu

Washington University in Saint Louis, St. Louis, MO, USA

2 Providence Portland Medical Center, Portland, OR, USA

3 Gannon University, Erie, PA, USA

4 Icahn School of Medicine at Mount Sinai, New York, NY, USA

5 Southern Illinois University, Edwardsville, IL, USA
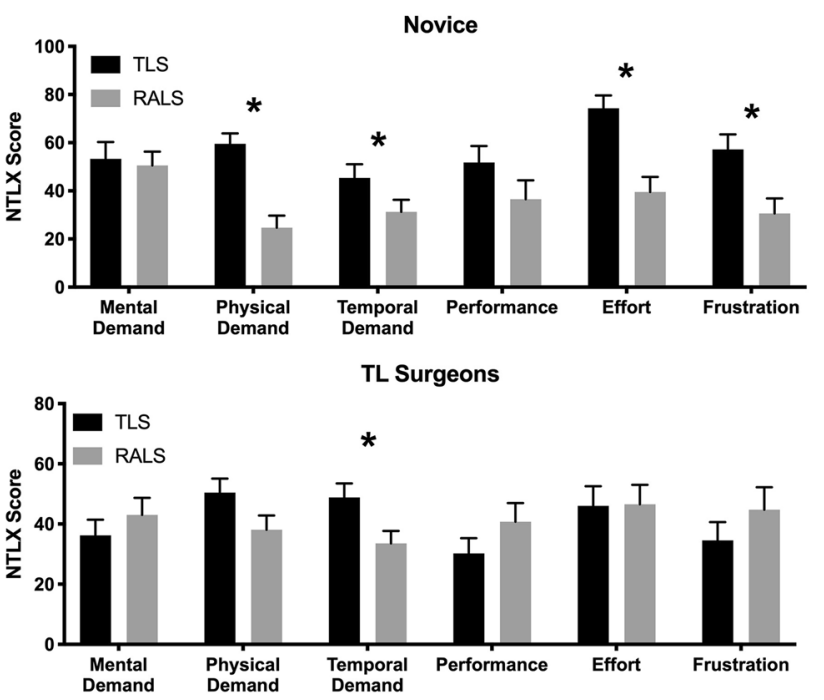

RAL Surgeons

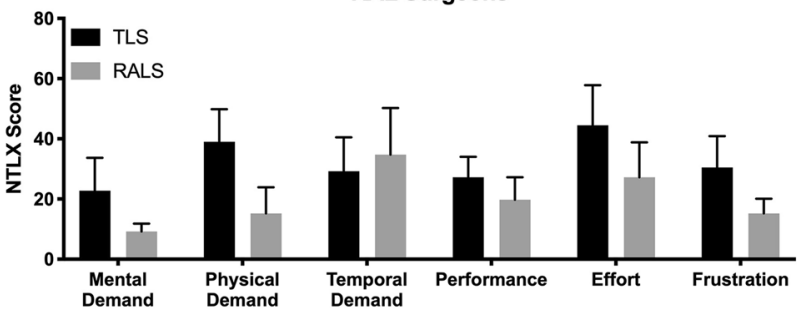

Fig. 2 Mean National Aeronautics and Space Administration Task Load Index (NTLX) scores for novices, traditional laparoscopic (TL) surgeons, and robot-assisted laparoscopic (RAL) surgeons during traditional laparoscopic surgery (TLS), and robot-assisted laparoscopic surgery (RALS). $* p<0.05$

Publisher's Note Springer Nature remains neutral with regard to jurisdictional claims in published maps and institutional affiliations. 